\title{
Formas bastardas: reportagem e vida
} anônima ${ }^{1}$

Marcio Serelle

1 A primeira versão deste texto foi apresentada no seminário A visibilidade dos anônimos, promovido pelo Grupo de Pesquisa Mídia e Narrativa, da Pontifícia Universidade Católica de Minas Gerais (PUC-MG), em Belo Horizonte, nos dias 06 e 07 de novembro de 2013.

2 Professor do programa de Pós-Graduação em Comunicação Social da PUC-MG, coordenador do grupo Mídia e Narrativa, da mesma instituição, e pesquisador do CNPq. marcio.serelle@gmail.com. 


\section{Resumo}

\section{Palavras-chave}

Reportagem, visibilidade, anonimato, campo.

\section{Abstract}

From its rising in modern times, the reportage has been considered a bastard form, due to its hybrid condition, found between fiction and fact. This essay investigates the notion of bastardy and argues that there is an injunction between the so called "impure genre" of some reportages and their aim at illuminating anonymous and abandoned social life. These narratives engender their own sensitive order - that is quite different from the sensitive in literature itself - while they highlight invisible people and social fields. Thus, this text evokes the notion of "fields" in Giorgio Agamben (2010), understood as being "zones of exception" in our society, where people live beneath a citizenship line and which are persistently denounced by the reportage.

\section{Keywords}

Reportage, visibility, anonymity, field. 
Desde sua emergência na modernidade, a reportagem, como um híbrido de fabulação e vontade de verdade, tem sido denominada como forma bastarda, na acusação de sua condição impura. No inquérito literário de João do Rio, em 1905, o poeta simbolista Nestor Vitor (2006) considerou-a um ramo "bastardo" da literatura, uma "literatura da informação", que, em obras como As religiões do Rio (do próprio João do Rio), Os sertões (Euclides da Cunha) ou No Japão (Oliveira Lima), plasmava a indecisão de seu tempo. A expressão retornaria em contexto bastante diverso e mais combativo, na década de 1960, na conhecida crítica de Dwight Macdonald a The Kandy-Kolored Tangerine-Flake Streamline Baby, obra de Tom Wolfe que considerava dúbia. Um dos aspectos polêmicos dessa não ficção era o uso da técnica modernista do fluxo de consciência. Como recupera Weber, Wolfe exibia-a como um trunfo, pois "sustentava que o cinema e a televisão haviam roubado muitas das funções das histórias e dos romances, mas algo que eles não conseguiram dominar foi o monólogo interior, a sensação de penetrar na consciência de um personagem" (WEBER, 1980, p. 29. tradução nossa)3. Segundo os novos jornalistas, a paisagem interior permanecia província da ficção - e também da não ficção. No entanto, para Macdonald, recursos como esse faziam dessas reportagens "formas bastadas", pois exploravam "a autoridade factual do jornalismo e a licença excitante da ficção" (MACDONALD, 1974, p. 223, tradução nossa)4.

A investigação de Adorno acerca do ensaio, então considerado um produto bastardo na Alemanha, pode nos ajudar a compreender o que conforma esse estigma. Para Adorno, a bastardia é um modo resistente e conservador de designar a forma que carece "de tradição convincente" (2003, p. 15) ou, nas palavras de Lukács, "aquilo que não conseguiu deixar para trás o caminho que leva à autonomia" (LUKÁCS apud ADORNO, 2003, p. 15). Esse tipo de "subliteratura" é, ainda, aquele que não se submete à antítese entre o sensível da arte e os modos mais organizadores de um conhecimento positivo. Assim, "o ensaio é, ao mesmo tempo, mais aberto e mais fechado do que agradaria

3 "(...) held that film and television had usurped many of the functions of stories and novels, but one thing they had not been to handle as interior monologue, the sense of being inside the consciousness of a character". 
ao pensamento tradicional" (ADORNO, 2003, p. 37). Como na epígrafe que Adorno retira de Goethe, o sujeito, em face de uma composição ensaística, está "destinado a ver o iluminado, não a luz", isto é, está destinado a ter com um pensamento que oferece sentidos aos pontos cegos de um objeto, e não com a explicação, sem que isso implique, de acordo com filósofo, que o ensaio assuma a própria forma artística.

A acusação de bastardia não se apoia, contudo, somente na incapacidade de a reportagem, notadamente aquela de grande investimento narrativo, estabelecerse como forma autônoma, na ultrapassagem de séries discursivas já estabelecidas, ou pela afronta que ela faz a pares antinômicos culturalmente (literatura e jornalismo; ficção e não ficção). A reportagem seria espúria porque rebaixada, ao servir menos à experiência viva do que ao imediato do jornalismo e do mercado. Macdonald considerou-a um produto pseudo-cultural feito na medida para o gosto de um público popular, isto é, como "entretenimento". Nessa passagem, as pessoas tornam-se personagens "manufaturadas para consumo do público com a cooperação entusiasmada dele" (MACDONALD, 1974, p. 231, tradução nossa) 5 .

Nisso, no que diz especificamente do texto bem ao gosto do público, a biografia - que é outra forma bastarda - aproxima-se da reportagem. Dosse (2009) considera que "um desprezo obstinado", por parte da comunidade de intelectuais, condenou a biografia como escrita de "mercenário", que faz concessões à emotividade e joga para a plateia. A força persuasiva dessas narrativas pode ser compreendida, em parte, pela valorização do factual como forma de mediação de experiências. Na explicação de Malcolm (2011, p. 149), o leitor da reportagem é capaz de aceitar a limitação estética desse relato, se comparada ao modo intenso, livre e imaginativo da ficção, com base na crença no caráter tido como edificante do gênero: a ideia de que se trata de "uma obra sobre algo que é verdadeiro, sobre coisas que realmente aconteceram e pessoas que de fato viveram ou vivem $(. . .)^{\prime \prime}$. No entanto, o fato de esses gêneros mais populares (em determinadas sociedades mais do que em outras) serem 
considerados bastardos não é coincidência, mas sugere, antes, uma clivagem, que acaba por remeter à origem germânica do termo "bastardia", situação configurada por um segundo casamento com mulher de classe "inferior".

Esses aspectos - a instabilidade entre séries discursivas, o arremate narrativo - colocam em relevo o caráter aporético da reportagem, que, conquanto seu contrato tácito de narrar sobre o que aconteceu, só consegue colocar de pé suas personagens quando ficcionaliza. Mas seu gesto é, em grande medida, diferente do da literatura. Lionel Trilling (2013) escreveu que a recepção inicial de Anna Kariênina aderiu à obra com entusiasmo quase infantil, pois os primeiros leitores apreenderam o romance de Tolstói não como obra de arte, mas como "parte da vida". "É assim que as coisas são", reconheceram. Esse é, em geral, o ponto de chegada do literário, exemplarmente do romance. Por meio de sua mediação refratária (mesmo quando realista), a literatura, como denominador comum da experiência, é capaz de dar forma ou claridade às coisas, àquilo que nos solda e de que de outro modo não poderia ser revelado.

Já o sensível da reportagem é de outra qualidade, pois sua imediaticidade demanda mais claramente intervenção, uma atitude prática. Quando bemsucedida, a reportagem - ou pelo menos um certo tipo de não ficção empenhada de que falaremos aqui - não é acompanhada de "é assim que as coisas são, isso é a vida", mas de "não é possível que as coisas sejam assim". Isso não quer dizer que o espaço literário é o da resignação, pois é também o do dissenso. A boa literatura é sempre "em revolta", no entender de um escritor (VARGAS LLOSA, 2009), e pode atuar de maneira humanizadora. No entanto, há um espaço imediato da ação - e esse é o ponto aqui - que a literatura (a ficção) não cobre, por mais que seja militante.

$\mathrm{Na}$ parte reflexiva da reportagem "Os vampiros da realidade só matam pobres", que escreveu sobre a atuação de Médicos sem Fronteiras na Bolívia, Eliane Brum (2012) expõe que, inicialmente, planejou um conto de terror, mas que a urgência da realidade da doença de Chagas no interior daquele país demandou um texto jornalístico que arrancasse aquelas pessoas/personagens 
(essa é uma relação não resolvida, de que se nutre a não ficção) da zona de invisibilidade. "Não pude traí-los. Então escrevi a história como eu a vi - e como me foi contada. Na esperança de que um dia ela possa virar ficção" (BRUM, 2012, p. 48). A reportagem, por seu caráter convocatório, pareceu à jornalista a forma mediadora mais apropriada para a circunstância.

De modo análogo, o crítico de arte Arthur Danto considera que "há coisas que seria quase imoral representar na arte justamente porque aí elas são representadas a uma distância que é exatamente incorreta do ponto de vista moral" (2010, p. 60). Segundo ele, não se pode propor ao público afastamento em face de uma injustiça a que temos a obrigação de intervir. Em certos casos, seria "errado ou mesmo desumano" assumir uma atitude estética diante de determinadas realidades, como, por exemplo, "ver uma manifestação de rua em que a polícia espanca os participantes como um balé, ou ver as bombas lançadas de um avião como se fossem crisântemos" (DANTO, 2010. p. 60). A partir do argumento de um dramaturgo, Danto desenvolve a questão:

Tom Stoppard disse certa vez que se você vê uma injustiça ocorrendo do lado de fora de sua janela, a coisa mais inútil que poderia fazer seria escrever uma peça de teatro a respeito. Eu iria mais longe, sugerindo que há algo errado em escrever peças de teatro sobre uma injustiça ante a qual tempos a obrigação de intervir, já que elas põem a plateia exatamente naquela espécie de afastamento que o conceito de distanciamento psicológico pretende descrever - argumento semelhante foi oferecido nas críticas feitas às fotografia de Diane Arbus (DANTO, 2010, p. 60).

Entre os escolhos do espetáculo (da sedução do horror) e da leviandade (do uso de personagens para "humanizar" uma história), a reportagem tenta se ajustar, narrativamente, como texto de intervenção. Sua problemática não está, portanto, pelo menos na abordagem proposta, no reconhecimento, ao modo da guinada linguística, de sua ficcionalidade, na relação entre literatura e jornalismo, que já nos parece dada. Mas na sua condição de "gênero contratual" - deslocando, aqui, a expressão de Lejeune (2008) acerca da autobiografia -, que, em sua formação na cultura, tem-se firmado num feixe de relações que 
envolve determinados limites imaginativos e balizas na fatura da narrativa, um modo de leitura que vincula texto e referências extratextuais e uma função social.

Historicamente, a condição rasteira da reportagem (narrativa tolhida, de "segunda categoria") constituiu também uma perspectiva, um modo de olhar de perto, em que a bastardia do gênero serviu à narração da vida anônima, em matizes diversos. Seu gesto frente ao anonimato já está inscrito no muckraking norte-americano, a reportagem que, na passagem do século XIX para o XX, iluminou os distritos miseráveis dos emigrantes. Para Inglis (2012), o muckraking (literalmente "remexer esterco com ancinho") deu ao jornalismo ocidental uma face popular e progressista, que se tornou uma espécie de mito da profissão e uma base a partir da qual a imprensa passa a ser julgada em seu comprometimento. Não queremos afirmar, com isso, que essa vertente da valorização da pequena história dos anônimos seja única na reportagem ${ }^{6}$, mas que ela persistiu com uma das vontades de conhecimento que caracterizou a modernidade do jornalismo. Podemos aplicar à reportagem a ideia de Paul Klee, para quem a forma moderna não ambiciona apenas registrar, mas tornar visível. Como explica Rouillé acerca do fotográfico - cujo uso documental e investigativo caminhou parelho com o da reportagem - essas visibilidades "correspondem a um esclarecimento das coisas: uma maneira de ver e de mostrar uma certa distribuição do opaco e do transparente, do visto e do não visto" (ROUILLÉ, 2009, p. 39).

Um traço do jornalismo brasileiro, de acordo com Sousa, é a "interseção entre fazer reportagem e descobrir a nação - seja nas cidades, seus arredores e

Convém destacar aqui duas falas, distantes temporal e culturalmente, que assinalam, de forma nada elogiosa, a obsessão de repórteres por personagens de condições antagônicas na vida. Primeiro, a de João do Rio, para quem, nas "sociedades organizadas", não interessava o homem de classe média, mas somente "a gente de cima e a canalha. Porque são imprevistos e se parecem pela coragem dos recursos e a ausência de escrúpulos" (RIO apud GOMES, 1996, p. 63). Dwight Macdonald, na crítica já citada ao livro de Tom Wolfe, advertia que os "novos jornalistas" exploravam as celebridades e os anônimos enfraquecidos, pois ambos apresentavam as mesmas vantagens, isto é, a "imprecisão [no relato sobre eles] não acarretará sérias consequências" [inaccuracy will have no serious consequences] (MACDONALD, 1974 , p. 231). Para o autor, as pessoas "pequenas" e comuns não ousam pensar em invasão de privacidade; as celebridades, pelo contrário, desejam, profissionalmente ou por vaidade, que sua privacidade seja invadida, pois, na condição de personagens (como em uma peça ou filme) e não de pessoas, elas necessitam de visibilidade e atenção. 
subterrâneos como em lugares 'ermos' do interior brasileiro" (SOUSA, 2010, p. 12). A tese de uma invisibilidade que insiste e que precisa ganhar volume até tornar-se sensível é, entretanto, um motor geral da reportagem. Pensemos nos nova-iorquinos anônimos de Talese (2004, p. 19) (em "uma cidade das coisas que passam despercebidas", "uma cidade dos esquecidos") - e, por afinidade, na investida de Vanessa Bárbara para revelar os passantes da rodoviária Tietê, em São Paulo, "uma cidade de coisas perdidas" (BÁRBARA, 2008, p. 11), em O livro amarelo do terminal; ou, ainda, nos colonos das plantações de algodão no Alabama, que o repórter James Agee e o fotógrafo Walker Evans pretenderam dar a conhecer em Elogiemos os homens ilustres. Para esses dois últimos, os trabalhadores do sul dos Estados Unidos integravam à época (1936) "uma parcela da população cuja existência mal se imagina[va]" (AGEE; EVANS, 2009, p. 12).

Em outro cotejo - e poderíamos apontar vários outros exemplos - Eliane Brum escreveu também sobre Roraima que esse é um estado desconhecido pelos demais brasileiros, "que mal suspeitam do que se passa nas sobrancelhas do país continental" (BRUM, 2008, p. 44). Roraima é um estado "orfão", tão "maltratado" e "isolado" que, quando um roraimense viaja, anuncia que "vai para o Brasil".

Em Ossos no deserto, obra de Sergio Gonzalez Rodríguez (2002), que reúne reportagens publicadas em primeira versão no jornal mexicano Reforma, sobre o assassinato sistemático de mulheres e crianças em cidade Juárez, na fronteira com os Estados Unidos, narra-se justamente para que as vítimas adquiram rosto, apesar da insensibilidade política e policial do território.

Em uma das reportagens, "Mortas sem fim", o anonimato que se busca romper é tratado metonimicamente a partir dos cartazes dos desaparecidos, em que nomes se confundem e "traços fisionômicos lutam por escapar dos claroescuros que a reprodução deficiente lhes confere" (GONZALEZ RODRÍGUEZ, 2002, p. 142, tradução nossa) . Para Gonzalez Rodríguez, a narrativa da reportagem é primordial como método de exposição e argumentação ética e moral para acessar e dar a ver as realidades humanas. 
No enfrentamento do horror, reportagens recentes como a do próprio Rodríguez, e também as de Roberto Saviano, na Itália, Anna Politkovskaya, na Rússia, e Daniela Arbex, no Brasil, colocaram em evidência a condição da vida que pode ser facilmente suprimida, posto que, como no homo sacer de Agamben (2010), situa-se "no cruzamento entre uma matabilidade e uma insacrificabilidade".

Figura enigmática do direito romano antigo, o homo sacer ou "homem sacro" é aquele que foi julgado pelo povo por um crime e que, quem o mata, não pode ser condenado por homicídio. Tampouco sua morte pode ser considerada sacrifício, pois aquilo que é sacer já pertence aos deuses - e de modo particular aos deuses considerados ínferos. O homo sacer é comparável ao wargus, o "lobo" do direito medieval alemão, um bandido que pode ser morto ou já considerado como morto. Na condição limite de homem-lobo, o bandido (etimologicamente, o banido) é um híbrido monstruoso entre o humano e o ferino, entre a cidade e a selva, entre a lei e a natureza. Num paroxismo, essas reportagens sinalizam, nas sociedades contemporâneas, esse mesmo limiar da indiferença.

Se, em Holocausto brasileiro, sobre o hospital Colônia, em Barbacena, a narrativa não alcança propriamente a "anatomia do sistema", o desfecho da reportagem possui a virtude de evocar a noção deslocadora de campo:

Os campos de concentração vão além de Barbacena. Estão de volta nos hospitais públicos lotados que continuam a funcionar precariamente em muitas outras cidades brasileiras. Multiplicam-se nas prisões, nos centros de socioeducação para adolescentes em conflito com a lei, nas comunidades à mercê do tráfico (ARBEX, 2013, p. 255).

Esse alerta da reportagem remete-nos à noção de campo em Agamben (2010), que convém recuperar aqui, ainda que brevemente. O campo, como lógica, são espaços lacunares em que os corpos habitam de forma paradoxal, pertencendo e não pertencendo a nenhum dos mundos, o que é também uma espécie de bastardia. Assim, o lager da Shoah torna-se não um espaço de catástrofe do passado histórico recente, mas a matriz oculta que faz da exceção, hoje, uma condição permanente. Para Agamben (2010), é preciso reconhecer essa matriz em suas 
metamorfoses, tanto nas chamadas "zonas de espera" dos aeroportos europeus - que fazem a humilhante triagem dos imigrantes - como em certas periferias de nossas cidades ou, de modo mais extensivo, nas populações do chamado terceiro mundo, submetidas, segundo ele, ao projeto democrático-capitalista que pretende eliminar as classes pobres. A exemplo do que fez Zizek (2003), podemos apontar outros "campos", tais como: guantânamos, campos de refugiados e cracolândias, entre outros espaços em que o sujeito está aquém da cidadania.

A essa forma de invisibilidade social sobrepõe-se, como tentamos argumentar até aqui, o anonimato midiático. Nesse contexto, a reivindicação de determinadas reportagens de romper com esse estado excludente é também a de deslocar uma forma considerada acomodada de jornalismo. Entre o programa moderno de redistribuição do visível e sua realização, há uma série de questões enfrentadas pela reportagem que não puderam ser abordadas, tais como: a dificuldade de intercambiar lugares no encontro jornalístico e o problema ético acerca do que fazer com essa voz do "outro"; a sedução por se encontrar no redemunho do horror, que, em muitas narrativas, acaba por cultivar um lugar retórico; a circulação e a sobrevivência dos relatos que, à distância, acabam por ganhar viés estetizante.

Para concluir, gostaríamos de afirmar justamente esse vínculo entre a forma bastarda da reportagem, no espaço que se delineia por meios das narrativas citadas, e a vida anônima, muitas vezes banida. Se a narrativa da reportagem tem sido, até o momento, bastante investigada pelo diálogo entre o jornalismo e a literatura, passemos ao reconhecimento de que a forma mista e flutuante da não ficção já é, hoje, estabelecida. No entanto, sua orientação sensível para "outro" e sua imediaticidade, bem como seu modo e leitura e os usos sociais e culturais que são feitos dela ainda precisam ser estudados. 


\section{Referências}

ADORNO, T. W. "O ensaio como forma". In: ADORNO, T. W. Notas de literatura. São Paulo: Duas Cidades; Ed. 34, 2003.

AGAMBEN, G. Homo Sacer: o poder soberano e a vida nua I. Belo Horizonte: Editora UFMG, 2010.

AGEE, J.; EVANS, W. Elogiemos os homens ilustres. São Paulo: Companhia das Letras, 2009.

ARBEX, D. Holocausto brasileiro - genocídio: 60 mil mortos no maior hospício do Brasil. São Paulo: Geração Editorial, 2013.

BÁRBARA, V. O livro amarelo do terminal. São Paulo: Cosac Naify, 2008.

BRUM, E. O olho da rua: uma repórter em busca da literatura da vida real. São Paulo: Globo, 2008.

BRUM, E. "Os vampiros da realidade só matam pobres". In: Dignidade. São Paulo: Leya, 2012. p. 25-50.

DANTO, A. A transfiguração do lugar-comum. São Paulo: Cosac Naify, 2010.

DOSSE, F. O desafio biográfico: escrever uma vida. São Paulo: Edusp, 2009.

GONZALEZ RODRÍGUEZ, S. Huesos en el desierto. Barcelona: Anagrama, 2002.

INGLIS, F. Breve história da celebridade. Rio de Janeiro: Versal, 2012.

LEJEUNE, P. O pacto autobiográfico: de Rousseau à internet. Belo Horizonte: Editora UFMG, 2008. 
MACDONALD, D. "Parajounalism or Tom Wolfe and his magic writing machine". In: WEBER, R. The reporter as artist. Toronto: Hasting House, 1974. p. 223233.

MALCOLM, J. O jornalista e o assassino. São Paulo: Companhia das Letras, 2011.

ROULLIÉ, A. A fotografia: entre documento e arte contemporânea. São Paulo: Senac, 2009.

SOUZA, C. V. Repórteres e reportagens no jornalismo brasileiro. Rio de Janeiro: FGV, 2010.

TALESE, G. Fama e anonimato. São Paulo: Companhia das Letras, 2004.

TRILLING, L. "Anna Kariênina". In: Serrote. São Paulo: Instituto Moreira Salles, jul. 2013. No. 14. p. 186-193.

VARGAS LLOSA, M. "É possível pensar o mundo moderno sem o romance?". In: MORETTI, F. O romance, 1: a cultura do romance. São Paulo: Cosac Naify, 2009.

VITOR, N. "Entrevista a João do Rio". In: RIO, J. O momento literário. Curitiba: Criar, 2006. p. 82-88.

WEBER, R. "A bastard form". In: WEBER, R. The literature of fact: literary nonfiction in American Writing. Athes, Ohio: Ohio University Press, 1980. p. 2733.

ZIZEK, S. Bem-vindo ao deserto do real. São Paulo: Boitempo, 2003. Da literatura ao cinema, anotações sobre a "dialética da malandragem" 